\title{
Waiting for rehab?
}

\author{
Steffan Davies, Simon Payne and Jane Jenkins
}

\begin{abstract}
If is a common bellef among staff in Noltingham's acute poychiatilic senvices that the Rehabilitation and Community Care Services (RCCS) are slow to respond to reterrals leading to blocking of acute beds. In response to this the authors examined 'bectblocking' while RCCS responded to referrats of acute in-patients and long stoys of existing RCCS patients admitted to ceute wards churing exacerbations of their iliness.
\end{abstract}

Nottingham Health Authority has a catchment population of approximately 620000 served by an integrated, community orientated psychiatric service (described in part by Tyrer et al, 1987). There are 146 adult acute beds including 12 beds for the district forensic service and six for the maternal mental illness service. There is a separate drug and alcohol service, and comprehensive elderly, child and adolescent. and learning disabilities services. The city has been sectorised for many years and each of the six sectors has two consultants, a multidisciplinary team and access to day hospital facilities.

The Rehabilitation and Community Care Services (RCCS) manage a wide variety of rehabilitation, community and continuing care facilities for around 500 patients with severe enduring mental illness. There are a variety of supported accommodation schemes, four long-stay NHS in-patient faclitities, and 20 beds for more disturbed patients run by the forensic service. A Dispersed Intenstvely Supported Housing (DISH) scheme provides intensive home support for patients in the community. Two units provide active residential rehabilitation. There are also four care management teams (Ford et al, 1993) and a variety of day facilities.

Previous examination of 100 consecutive referrals to RCCS (Repper, personal communication) showed that only $16 \%$ were in-patients at the time of referral ('bedblocking' was not examined). An initial assessment by a care manager and team member from the appropriate unit was carried out within four weeks for $90 \%$ of referrals. The majority of this group was living independently or with family support. They were referred to a variety of RCCS facilities including day care (46\%) and general assessment (8\%) but $47 \%$ were referred for residential placements.
Table 1. Age and gender distribution

\begin{tabular}{lcl}
\hline Age & Male & Femole \\
\hline$<25$ & 4 & 11 \\
$25-34$ & 20 & 14 \\
$35-44$ & 7 & 11 \\
$45-54$ & 7 & 8 \\
$>55$ & 4 & 15 \\
Total & 42 & 59 \\
\hline
\end{tabular}

\section{The study}

Using hospital activity and case register data we identified all patients with admissions in 1990 of over 90 days. We also included patients who had three or more admissions in 1990 as they may also have severe enduring mental illness but may not have met the duration criteria. If any of the multiple admissions were over 90 days these patients would become part of the prolonged group. 'Bedblocking' figures were calculated from the date on the referral letter - the only consistently recorded data. The case notes were examined by the authors and data collected for admissions starting in 1990 with a census date of 1 March 1992; 1990 was the latest year for which complete data was available.

Active residential rehabilitation placements usually last 6-12 months. The time scale for assessment which includes visits and trial leaves to the facility is therefore reasonably several weeks. Long-stay facilities run at near $100 \%$ occupancy and transfer is largely determined by availability of beds at the time of referral. Given these factors we felt a reasonable standard for our audit was of eight weeks (56 days) from referral to final discharge to a RCCS facility.

\section{Findings}

Overall, 102 patients were identified, 71 with prolonged and 31 with multiple stays. All but three sets of notes were recovered and there was information avallable from other sources on these patients. The impact of this group on acute bed occupancy is described elsewhere (Davies, 1994). These 102 patients occupied 16794 bed days. which was approximately $40 \%$ of the occupied 
bed days in the acute unit in 1990 . The age and gender distribution are given in Table 1.

Forty-five per cent of the sample suffered from schizophrenia or schizoaffective disorder, $43 \%$ from affecttve disorder and $10 \%$ from organic disorders, personality disorder or other diagnoses.

Of the 102 patients five were already patients of RCCS who required readmission. Sixteen were referred to RCCS during the admissions studied and 13 of these accepted the service. Five were subsequently referred to RCCS of whom three accepted the service. In terms of bed blocking it is helpful to examine these groups separately.

\section{Referrals}

Thirteen patients accepted the service following referral. The nine who moved on to residential rehabilitation placements occupied 548 beddays, an average wait of 61 days (range 25-114). The two waiting for a place in the longer-term DISH scheme waited just 13 days on average (range 0-26) as there were vacancles in the service at that time. The one patient who moved to a continuing care bed waited for 66 days but was referred to a unit dealing with less disturbed patients. One patient waited 17 days before discharge with care management support. The average waiting time from referral to transfer or discharge under RCCS care was $\mathbf{5 0}$ days. Two patients who refused the service spent 69 days in total on the acute wards before this decision was reached. One patient waited for 160 days for a continuing care bed but was placed in a registered home by the sector team before one became available.

\section{RCCS patients}

The five RCCS patients who required multiple or prolonged readmission occupied 1006 acute bed days. The first was a woman who was placed with her family and subsequently beame pregnant; she was admitted to the mother and baby unit where she remained for 100 days. Problems persuading the family of her needs delayed discharge. One patient had four brief admissions and his care was subsequently transferred to the forensic service. Another patient required four acute admissions for a manic depressive illness from the supported housing project in which he was placed. The last two patients were admitted from continuing care faclitiles and both remained on acute wards for over $\mathbf{3 0 0}$ days while awaiting alternative continuing care placements. These last two patients can be regarded as blocking acute beds for considerable lengths of time but move on was delayed by the saturation of the appropriate long-stay facilities.

\section{Outcomes}

On the census day in March 1992, the vast majority ( $n=93 ; 91 \%)$ of patients were still in contact with mental health services in Nottingham. Six patients had died, two of suicide and four of natural causes, two had moved districts. Two (10\%) of the 21 patients in RCCS were acute in-patients compared with $11(14 \%)$ of those not referred. Four (18\%) of the RCCS patients were in single or family accommodation as were 48 (60\%) of the acute group. All others were in some form of supported accommodation, two were lost to follow-up.

\section{Findings}

These results show that the average length of time from initial referral to RCCS to a move from an acute ward was 50 days in 1990. An average of 61 days for an active residential rehabilitation placement compared with our audit target of 56 days is encouraging. However, the longest wait of 114 days for residential rehabilitation leaves room for improvement. A different set of limitations apply to continuing care beds which are an expensive and finite resource. This is recognised by the inclusion of acute services representatives on the admissions panel and consequently ownership of their decisions by the unit as a whole. The waits of 300 days plus for continuing care faclities reflect near saturation in some of these facllities, particuarly those for more disturbed patients.

The 657 bed-days 'blocked' between referral and moving into RCCS facilities account for less than $4 \%$ of the bed-days occupied by the group we identified (and only $1.2 \%$ of total occupied acute bed-days). The issue of readmitted RCCS patients blocking acute beds seems to be of less importance as only five patients of the 102 identified were RCCS patients and the only significant blocking occurred in those awaiting long-stay beds for more disturbed patients. This compares favourably with prolonged acute stays by seven patients of 34 discharged to hostel accommodation from Frien Hospital to the (smaller) Hampstead Health Authority (Sheppard, 1993). There were other RCCS patients admitted for acute treatment during this period but none met the multiple or prolonged criteria for our study. It is therefore unlikely that they 'blocked' acute beds for any significant period.

It is interesting that so few of these patients were referred initially and why so few of the referrals examined by Repper were in-patients. It may be that perceptions of long waits for acceptance into RCCS inhibit referrals as while this is in process alternative discharge plans may be difficult to pursue. There is also a natural reluctance to hand over the care of patients to 
another team, particularly when a great deal of time and effort has been invested in their care. However, these patients have continued to have long-term mental health needs and by the census date of lst March 1992, 22\% of the total group had been referred, and $27 \%$ of the prolonged stay group.

\section{Comment}

Our study shows that although there was often a long wait for continuing care facilities in Nottingham Mental Health Unit, the same is not true of the active residential rehabilitation services. The average move on time of $\mathbf{5 0}$ days from referral, although long by acute standards, is not excessive given the long-term nature of the service provided. The small number of patients in the service identified as requiring prolonged or multiple admissions subsequently, points to the success of the service in preventing further prolonged acute admissions. Locally, various internal surveys have identified patients who may benefit from RCCS services who are not being referred; hopefully this study will remove one percetved obstacle to the referring teams. Nationally this stengthens the case for providing more rehabilitation and continuing care services as a means of reducing pressure on acute beds.

\section{References}

Davies, S., Payne, S. \& JenkINS, J. (1994) Impact of new long-stay patients. British Joumal of Psychlatry, 168. 841.

Ford, R. BEARDsmOORE, A., NORTON, P., et al (1993) Developing case management for the long-term mentally ili. Psychiatric Bullettr, 17, 409-411.

SHEPPARD, R. (1993) Readmissions of long-stay poychitatic patients to the acute services from hostels in the community. Psychiatric Bullettin, 17, 524-525.

TYRER, P.. TURNER, R. \& JOHNSON, A. L. (1989) Integrated hospital and community poychiatric services and use of inpatient beds. British Medical Journal, 299, 298-300.

Steffan Davies, Registrar, "Simon Payne, Consultant Rehabilitation Psychiatrist; and Jane Jenkins, Medical Audit Assistant; Mapperley Hospital, Porchester Road, Nottingham NG3 6AA

*Correspondence 